\title{
Heart Rate Variability Responses in Vertical Jump Performance of Basketball Players
}

\author{
Anderson Pontes Morales ${ }^{1,2,3, *}$, Felipe Sampaio-Jorge ${ }^{1,2,3}$, Luiz Felipe da Cruz Rangel ${ }^{1,2}$, \\ Gabriela Morgado de Oliveira Coelho ${ }^{1}$, Tiago Costa Leite ${ }^{1}$, Beatriz Gonçalves Ribeiro ${ }^{1}$
}

\author{
${ }^{1}$ Laboratory Research and Innovation in Sports Sciences, Federal University of Rio de Janeiro-Macaé Campus, Macaé, 27930-560, Brazil \\ ${ }^{2}$ Sports and Tourism of Foundation of Macaé, The Municipality of Macaé, Macaé, 27937-180, Brazil \\ ${ }^{3}$ Laboratory of Movement Analysis ISECENSA, Higher Institutes of Education of Censa, Campos dos Goytacazes, 28035-310, Brazil
}

\begin{abstract}
Our objectives were to investigate the acute responses of the heart rate variability (HRV) before, during and after the execution of different Vertical Jump (VJ) protocols and correlate the levels of sympathetic and parasympathetic modulation after the VJ execution with the performance variables in VJ. Eight male athletes $(29 \pm 4.9$ years; $186 \pm 8.6 \mathrm{~cm}$; $24.8 \pm 2.1 \mathrm{~kg} . \mathrm{m}-2 ; 12 \pm 1.2 \%$ body fat) of a team participating in the first division of the National Basketball League (NBL), from Brazil, were evaluated. For the HRV analysis, each subject was instructed to stand in a orthostatic position on the jump platform System Optical (Cefise ${ }^{\circledR}$, São Paulo) for a period of 10 minutes of rest before (R1) and after the VJ executions (R2). Right after the R1 period, athletes performed 5VJ with five seconds intervals (total time $\sim 30$ seconds) between $\mathrm{VJ}$ (5VJ) and then underwent 60 seconds of maximum continuous VJ (60SVJ). The HRV were automatically transferred and analyzed by the softwares "Polar ProTrainer5"M" (version 5.41.002., Kempele, Finland) and HRV analisys (version 2.1., Kuopio, Finland), respectively. The HFnu was used to represent the parasympathetic modulation, whereas LFnu represented the sympathetic modulation. The ratio LF:HF was used to represent the balance between sympathetic and parasympathetic modulations. The one-way Analysis of Variance (ANOVA) with post hoc Tukey test was used to compare differences in HRV during the execution of the experimental protocol. Linear regression and Pearson's correlation coefficient were used between the VJ performance variables (mean of $5 \mathrm{VJ}$ and $60 \mathrm{SVJ}$, jumps` number and fatigue index) and the sympathetic and parasympathetic modulation LF:HF R2 ( $<<0.05)$. The following comparisons of the HRV were found between the different

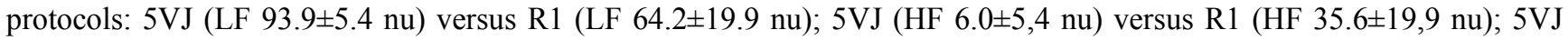
(LF:HF 40.1 \pm 37.4 ) versus R1 (LF:HF 2.6 $\pm 1.9 \mathrm{nu})(\mathrm{p}<0.001)$; $60 \mathrm{SVJ}$ (LF:HF $8.3 \pm 13.8 \mathrm{~ms}^{2}$ ) versus 5VJ (LF:HF $40.1 \pm 7.7$ $\left.\mathrm{ms}^{2}\right)$; R2 (LF:HF 6.5 $5.7 \mathrm{~ms}^{2}$ ) versus 5VJ (LF:HF $\left.40.1 \pm 7.7 \mathrm{~ms}^{2}\right)(\mathrm{p}<0.001)$. A significant correlation was found between the average height of $5 \mathrm{VJ}$ with the sympathetic and parasympathetic modulation LF:HF R2 $(r=0.7942, p=0.01)$ and fatigue index 60SVJ with the sympathetic and parasympathetic modulation LF:HF R2 $(r=0.7206, p=0.04)$. It is concluded that the $5 \mathrm{VJ}$ test characterized by intermittent high intensity loads, showed high significant responses of sympathetic modulation (LF; LF:HF) compared to the 60SVJ protocol. The $5 \mathrm{~min}$ recovery was not sufficient for the onset of vagal tone (parasympathetic modulation), which was accompanied by higher fatigue index presented by basketball athletes.
\end{abstract}

Keywords Heart Rate Variability, Vertical Jump, Basketball

\section{Introduction}

The Vertical Jump (VJ) is one of the most common actions performed by basketball players. For example McInnes et al [26] found that, on average, a basketball player performs 46 VJ per game. Authors like Ben Abdelkrim; El Fazaa and El Ati [2] reported an average of $44 \mathrm{VJ}$.

The physiological demands during a basketball game are characterized by production of repetitive force levels [24].

* Corresponding author:

andersonmrl@hotmail.com (Anderson Pontes Morales)

Published online at http://journal.sapub.org/sports

Copyright (C) 2014 Scientific \& Academic Publishing. All Rights Reserved
Thus, it becomes possible for the athlete to execute a greater number of $\mathrm{VJ}$ repetitions in offensive and defensive action a specific period of execution, without the implementation of fatigue processes and also be able to recover quickly after, and during continuous and intermittent high-intensity efforts [38]. Therefore, one of the basketball players' aim during the game is to improve their ability to perform a greater number of VJ with a lower level of muscle fatigue [39].

It is suggested that muscle fatigue blocks the increase in VJ performance $[35,29]$. The monitoring of the Autonomic Nervous System (ANS) responses can provide useful information about acute or chronic changes in training status [3]. It has been observed that the ANS is sensitive to changes in training loads $[25,18]$ and it seems to be an important 
variable for the individualized training prescription [21]. Furthermore, the ANS analysis in the period prior to a training program had a positive relationship with increased cardiorespiratory capacity after training, in non-athletes [16], suggesting that the assessment of the ANS may be an important "tool" to predict the onset of muscle fatigue during the execution of successive VJ.

At rest and at intervals of VJ executions, the heart's activity is regulated primarily by parasympathetic vagal branch of the ANS. During the execution of VJ intermittent high-intensity exercises, an increase in heart rate and stroke volume is required to meet the metabolic demands of skeletal muscles, thus, a response is triggered by ANS with a vagal withdrawal followed by sympathetic dominance [14]. Immediately after the workout session or during continuous VJ exercises, there is a vagal activity return $[19,12,7]$. Within this perspective, individuals with a predominant vagal activity may display a higher level of tolerance to muscle fatigue $[13,10]$.

The evaluation of the heart rate variability (HRV) describes the changes of HR, through the analysis of $\mathrm{R} R$ intervals, demonstrated by electrocardiogram tracing, which is used to measure the ANS function of the ANS. This "tool" has been shown to predict the physical shape, helping to evaluate the results of physical training [19, 3, 17]. However, most research in this area is traditionally focused on clinical situations due to its relationship with cardiovascular disease $[34,8,9,36,33]$. Studies that investigate the acute responses of $\mathrm{HRV}$ in the VJ performance, where the sport involves contributions from intermittent and continuous activities such as basketball, have not been fully explored. Given this background, the objectives of this research are: to investigate the acute responses of the autonomic activity indices before, during and after the execution of different VJ protocols; to correlate the levels of sympathetic and parasympathetic modulation after the VJ execution with the performance variables in $\mathrm{VJ}$.

\section{Methods}

\subsection{Subjects}

Eight male athletes of a team participating in the first division of the National Basketball League (NBL), from Brazil, were evaluated. Descriptive statistics are presented in Table 1. All participants volunteered for this study, which was approved by the Committee for Research Ethics Concerning Human Subjects, by the local university. Data were collected during two visits to the laboratory. The subjects presented themselves healthy, free of cardiopulmonary, metabolic, and orthopedic diseases. Furthermore, they did not use medications frequently. Prior to visiting the laboratory, subjects were instructed not to consume alcoholic beverages or sympathomimetic drugs for 12 hours before testing.

\section{Interval \\ $2 \mathrm{sec}$.}

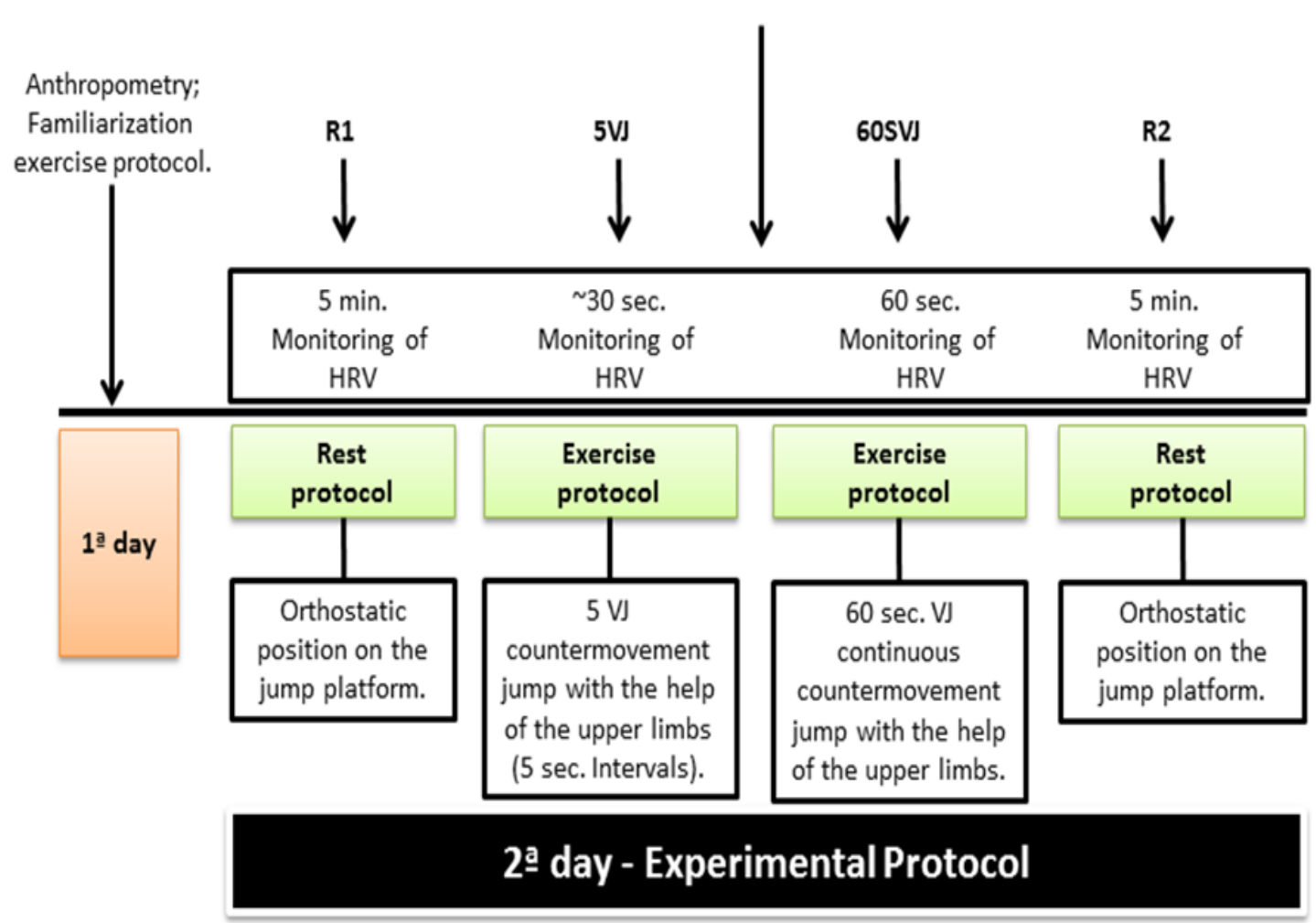

Figure 1. Experimental design. R1 - Rest before the exercise protocol; 5VJ - Five vertical jumps; 60SVJ - 60 seconds vertical jumps; R2 - Rest after the exercise protocol 
In the first visit to the lab, the athletes' height and body mass were measured (to the nearest $0.1 \mathrm{~cm}$ ) by a wall stadiometer (SECA) and a digital scale (to the nearest $0.1 \mathrm{~kg}$ ) (TANITA UM-061). The Body Mass Index (BMI) was calculated using the data of body weight divided by height squared $\left(\mathrm{kg} \cdot \mathrm{m}^{-2}\right)$. The percentage body fat (BF) was estimated by the seven point skin fold method, described by established guidelines [1].

\subsection{Procedures}

\subsubsection{Heart Rate Variability}

For the HRV analysis, each subject was instructed to stand in a orthostatic position on the jump platform for a period of 10 minutes of rest before (R1) and after the VJ executions (R2). Right after the R1 period, athletes performed $5 \mathrm{VJ}$ with five seconds intervals (total time $\sim 30$ seconds) between $\mathrm{VJ}$ $(5 \mathrm{VJ})$ and then underwent 60 seconds of maximum continuous VJ (60SVJ). The HRV analyses were performed between R1 and R2 in the last 5 minutes, during $5 \mathrm{VJ}$ and $60 \mathrm{SVJ}$ protocols. HRV was monitored continuously during the experimental protocol, except in the interval between $5 \mathrm{VJ}$ and $60 \mathrm{SVJ}$ (interval, 2 seconds) (Figure1). The analyses followed the guidelines for the HRV assessment [37]. The HRV were automatically transferred and analyzed by the softwares "Polar ProTrainer5"T" (version 5.41.002., Kempele, Finland) and HRV analisys (version 2.1., Kuopio, Finland), respectively. The power spectral density was quantified using the Fast Fourier Transform (FFT). The frequency bands of high HFnu $(0.15-0.40 \mathrm{~Hz})$ and low LFnu $(0.04-0.15 \mathrm{~Hz})$ spectrum were normalized $(\mathrm{nu})$ and recorded, respectively. The ratio between the low and the high frequency rate (LF:HF) was recorded in absolute units $\left(\mathrm{ms}^{2}\right)$ and included in the data analysis. The HFnu was used to represent the parasympathetic modulation, whereas LFnu represented the sympathetic modulation. The ratio LF:HF was used to represent the balance between sympathetic and parasympathetic modulations [37].

The subjects' heart rate was assessed by the Polar S810 heart rate monitor (Polar Electro Oy®, Kempele, Finland). This assessment tool was validated by electrocardiogram (ECG) regardless of position (supine and orthostatic test) of the evaluated $(p>0.05)$, showing a strong correlation ( $r>$ $0.97, \mathrm{p}<0.05)$ [11].

\subsubsection{Vertical Jump Performance}

The VJ performance was evaluated by the jump platform System Optical (Cefise ${ }^{\circledR}$, São Paulo). This equipament consists of a laptop with the software "Jump System" (version 1.0, São Paulo, Brazil), connected by a cable to a resistive (or capacitative) platform (equipped with infrared optical sensors). The timer software is triggered by the feet of the subject at the moment of release from the platform, and will be stopped at the moment of touch down. This equipment has the same principle of "Ergojump" [4] to inform the flight time (ms) and contact (ms). The error of measurement, when compared with film analysis has been reported to be in the order of $\pm 2 \%$ [22]. Athletes performed the countermovement jump technique in both protocols $(5 \mathrm{VJ}$ and 60SVJ). The athlete was positioned, barefoot, in the interior of platform and the jumps were performed starting from a standing position until approximately at an angle of $90^{\circ}$ knee, using help from upper limbs at the time of the $\mathrm{VJ}$ execution. All participants were familiarized with these procedures on the 1 st visit to the lab. In $5 \mathrm{VJ}$, the average height of the $5 \mathrm{VJ}$ was used. In $60 \mathrm{SVJ}$, we used the average height, the jumps' number $(\mathrm{JN})$ and the fatigue index (FI) of the VJ performed during 60 seconds. The FI was calculated by the following adapted equation, described by Bosco; Luhtanen and Komi [5]:

$$
\text { FI \% }=(\text { VJ 45-60sec. / VJ 0-15sec.) x (100) } 100
$$

In which VJ 45-60sec. $(\mathrm{cm})$ is the average height of the VJ performed during the last 15 seconds of effort in the $60 \mathrm{SVJ}$ test; VJ $0-15 \mathrm{sec} .(\mathrm{cm})$ is the average height of the VJ performed during the first 15 seconds of effort in the $60 \mathrm{SVJ}$ test.

\subsection{Statistical Analyses}

Data were entered in SPSS 16.0 software for statistical analysis. Descriptive statistics (mean $\pm \mathrm{SD}$ ) was determined for the following variables: age (years), height $(\mathrm{cm})$, weight $(\mathrm{kg})$, BMI $(\mathrm{kg} \mathrm{m}-2)$, percentage body fat $(\%)$, mean of $5 \mathrm{VJ}$ (cm) and 60SVJ, jumps' number and fatigue index (\%). The Shapiro-Wilk test was used to verify data normality. The one-way Analysis of Variance (ANOVA) with post hoc Tukey test was used to compare differences in autonomic activity during the execution of the experimental protocol. Linear regression and Pearson's correlation coefficient were used between the VJ performance variables (mean of $5 \mathrm{VJ}$ and 60SVJ, jumps' number and fatigue index) and the sympathetic and parasympathetic modulation LF:HF R2. Statistical significance for all tests was set at $\mathrm{p}<0.05$.

\section{Results}

Table 1 represents the descriptive statistics of anthropometric and $\mathrm{VJ}$ values.

Table 1. Descriptive statistics (Mean \pm SD) for the basketball players

\begin{tabular}{cc}
\hline Anthropometric variables & $(\mathrm{n}=8)$ \\
\hline Age $(\mathrm{yrs})$ & $29 \pm 4.9$ \\
Height $(\mathrm{cm})$ & $186 \pm 8.6$ \\
Weight $(\mathrm{kg})$ & $85.9 \pm 9.7$ \\
BMI $\left.\mathrm{kg} \mathrm{m}^{-2}\right)$ & $24.8 \pm 2.1$ \\
Body Fat $(\%)$ & $12 \pm 1.2$ \\
\hline Vertical jump variables & $(\mathrm{n}=8)$ \\
\hline 5VJ $(\mathrm{cm})$ & $49.0 \pm 5.8$ \\
60SVJ (cm) & $32.5 \pm 3.4$ \\
JN 60SVJ & $80.9 \pm 8.6$ \\
FI 60SVJ (\%) & $6.5 \pm 5.7$ \\
\hline
\end{tabular}

$\mathrm{JN}$ - jumps` number; FI- fatigue index 
Figure 2 represent the mean differences in the variables of HRV VJ experimental protocol. Following values of the differences between the $\mathrm{VJ}$ protocols of exercises $\mathrm{R} 1,5 \mathrm{VJ}$, 60SVJ and R2: 5VJ LF $93.9 \pm 5.4$ nu versus R1 LF $64.2 \pm$ $19.9 \mathrm{nu} ; 5 \mathrm{VJ}$ HF $6.0 \pm 5,4 \mathrm{nu}$ versus R1 HF $35.6 \pm 19,9 \mathrm{nu}$; 5VJ LF:HF $40.1 \pm 37.4$ versus R1 LF:HF $2.6 \pm 1.9 \mathrm{nu}(\mathrm{p}<$ $0.001)$; 60SVJ LF:HF $8.3 \pm 13.8 \mathrm{~ms}^{2}$ versus 5VJ LF:HF 40.1 $\pm 7.7 \mathrm{~ms}^{2}$; R2 LF:HF $6.5 \pm 5.7 \mathrm{~ms}^{2}$ versus 5VJ LF:HF $40.1 \pm$ $7.7 \mathrm{~ms}^{2}(\mathrm{p}<0.001)$.

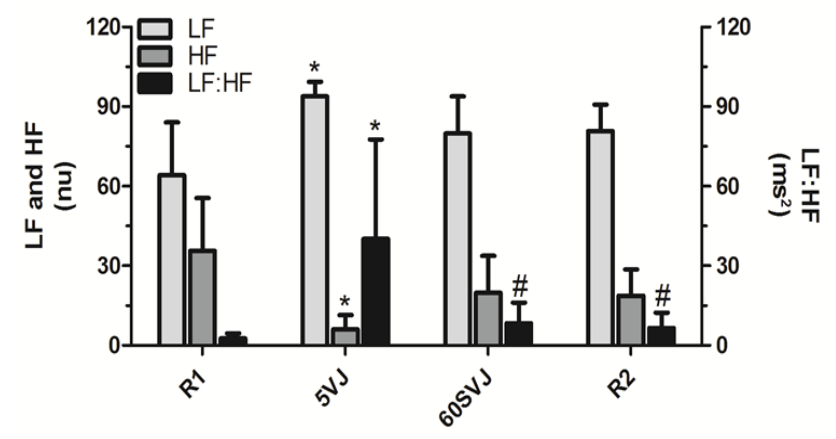

Figure 2. The heart rate variability (HRV) parameters between the VJ exercises protocols. R1 - Rest before the exercise protocol; 5JV - Five vertical jumps; 60SVJ - 60 seconds vertical jumps; R2 - Rest after the exercise protocol. LFnu $=$ low frequency power of HRV; HFnu $=$ high frequency power of $\mathrm{HRV}$; $\mathrm{LF}: \mathrm{HF}=$ high frequency power to low frequency power of HRV. (*) significantly different than R1 $(\mathrm{p}<0.001)$; (\#) significantly different than $5 \mathrm{VJ}(\mathrm{p}<0.001)$

Figure 3 shows the relationship of variables in VJ performance (mean of $5 \mathrm{VJ}$ and $60 \mathrm{SVJ}$ test; mean of the jumps` number and fatigue index from the 60SVJ test) and
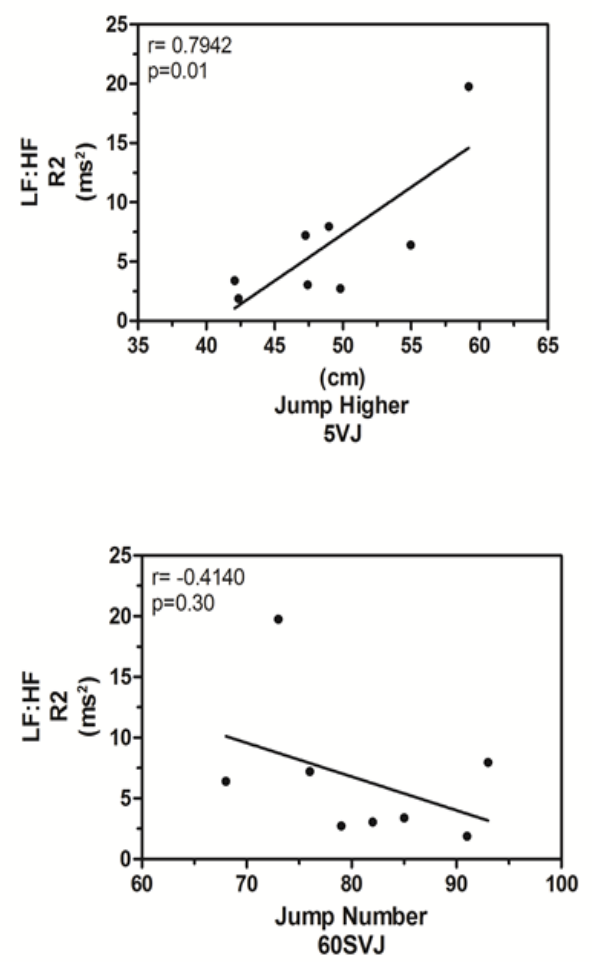

sympathetic to parasympathetic modulation LF:HF R2 ( $\mathrm{n}=$ 8). The correlation was significant for Jump Higher $5 \mathrm{VJ}$ ( $\mathrm{r}$ $=0.7942 ; p=0.01)$ and Fatigue Index 60SVJ $(r=0.7206 ; p$ $=0.04)$. The correlation was not significant for Jumper Higher 60SVJ $(r=-0.1345 ; p=0.75)$ and Jumps ` Number $(r$ $=-0.4140 ; \mathrm{p}=0.30$ ).

Figure 4 shows the changes of qualitative data on the behavior of high-frequency power (in yellow color). In protocol vertical jump $60 \mathrm{SVJ}$, the spectrum of high frequency is greater than the one from other protocols (R1, $5 \mathrm{VJ}$ and R2). Clearly, reactivation of vagal flow in $60 \mathrm{SVJ}$ protocol is observed.

\section{Discussion}

The main interest of assessing levels of HRV is related to the prognosis of cardiovascular diseases [9, 36, 33]. However, the literature is expanding these assessments to the contexts related to the generation of muscle strength and cardiorespiratory fitness in athletes, because of its ability to monitor the status of physical training $[19,21,3,7]$. The main findings of the study indicate that the $5 \mathrm{VJ}$ test characterized by intermittent high intensity loads, revealed differentiated responses of autonomic activity (LF; HF; $\mathrm{LF}: \mathrm{HF}$ ) regarding continuous protocol of $\mathrm{R} 1, \mathrm{R} 2$ and $60 \mathrm{SVJ}$ that verified the resistance explosive strength. Other responses found were the correlations between sympathetic to parasympathetic modulation LF:HF R2 with the higher averages in $5 \mathrm{VJ}$ and greater fatigue index in $60 \mathrm{SVJ}$ test.
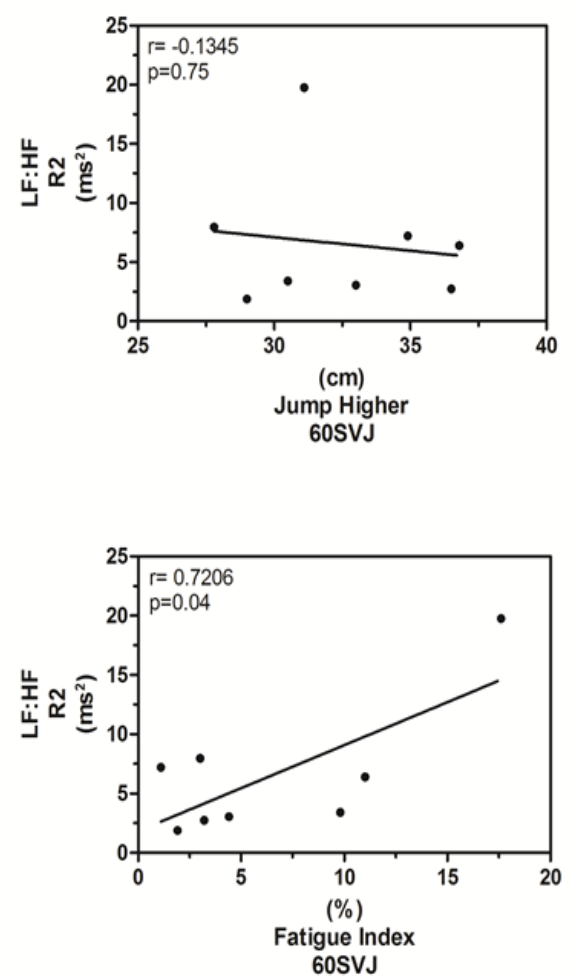

Figure 3. Correlation between the variables in VJ performance (mean of $5 \mathrm{VJ}$ test; mean of the jumps 'number and fatigue index from the $60 \mathrm{SVJ}$ test) and sympathetic to parasympathetic modulation LF:HF R2 

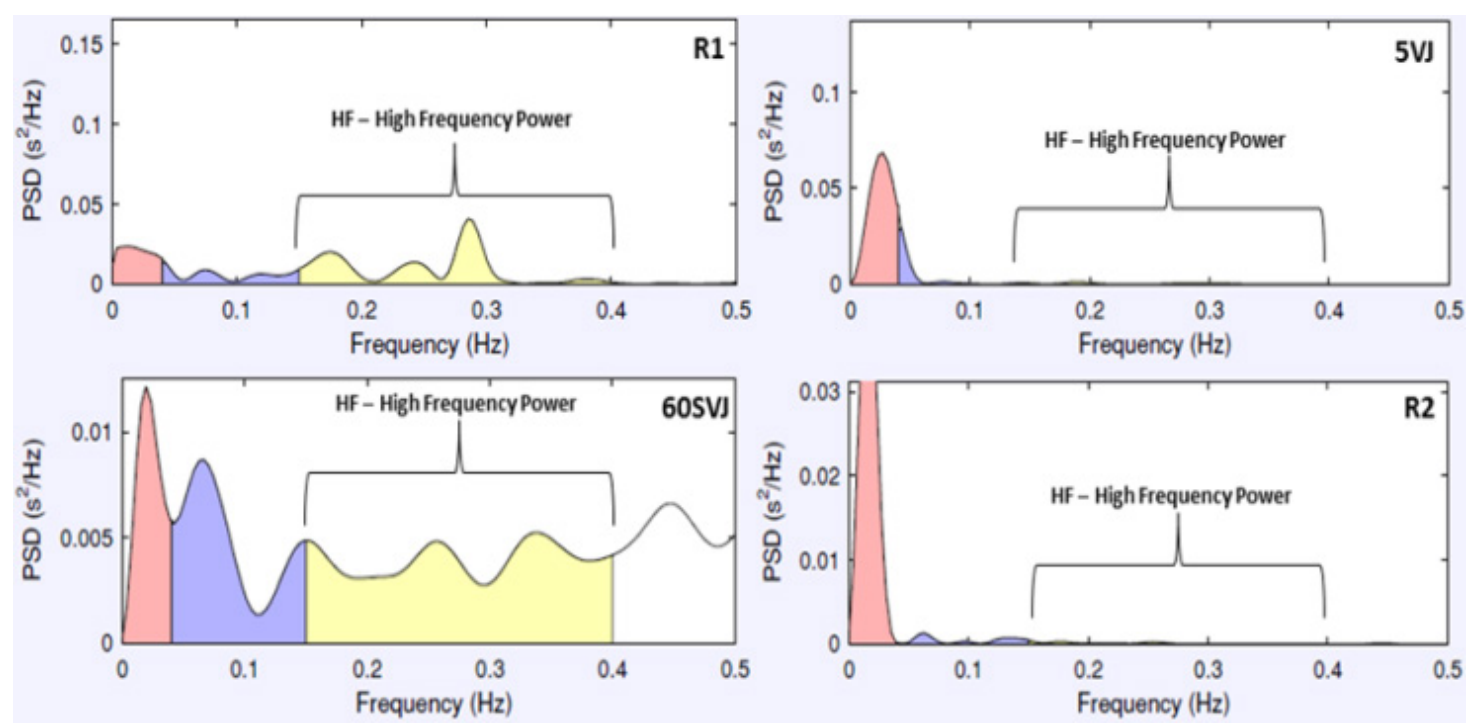

Figure 4. Examples of the power spectral of heart rate variability HRV in vertical jumps in basketball athletes. The vagal (i.e., HF $=$ high frequency power) tone is increased in R1 and 60SVJ. R1 - Rest before the exercise protocol; 5JV - Five vertical jumps; 60SVJ - 60 seconds vertical jumps; R2 - Rest after the exercise protocol

The increased autonomic responses LF; LF:HF presented by the athletes during the execution of the $5 \mathrm{VJ}$ protocol, characterized by intermittent high intensity loads, can be explained due to the need to meet the metabolic demands of skeletal muscles to generate maximum force for the $\mathrm{VJ}$ execution (Figure 2) [14]. There is strong evidence that changes in parasympathetic modulation (i.e., vagal withdrawal) during the execution of the $5 \mathrm{VJ}$ protocol are related to local factors and adrenergic metabolites (epinephrine, norepinephrine, $\mathrm{H}+$, lactate, iP). Buchheit; Laursen and Ahmaidi [6] showed that anaerobic exercise (lactate: $10.9 \pm 0.9$ mmol. $\mathrm{L}^{-1}$ ) were associated with a low level of parasympathetic modulation reactivation, whereas the moderate intensity exercise (lactate: $3.5 \pm 0.2 \mathrm{mmol} . \mathrm{L}^{-1}$ ) induced a more rapid rate of parasympathetic modulation reactivation. Authors like, Kawada et al [20]; Miyamoto et al [27]; Miyamoto et al [28] explain that in the presence of sympathetic activation, vagal stimulation essentially depends on the type and location of the most activated adrenergic receptors. For example, Miyamoto et al [27] showed that the dynamic response of vagal stimulation can be attenuated through activation of postganglionic receptors by high levels of plasma norepinephrine, but not by stimulation of the postganglionic cardiac sympathetic nerve [28]. Unfortunately, in this study it was not possible to evaluate the stress of the system (i.e., hormones and muscle metabolites) to verify the level of specific contribution on markers of HRV influencers. Thus, we attributed that the low level of parasympathetic reactivation observed during the execution of the $5 \mathrm{VJ}$ protocol by athletes, may be in part given to high sympathetic activity associated with the accumulation of metabolites.

However, VJ achieved by athletes, during the $60 \mathrm{SVJ}$ continuous protocol, showed a vagal reactivation (i.e., reduced LF:HF modulation and increased HF modulation) (figure 2 and figure 4) compared to $5 \mathrm{VJ}$ protocol. These observed acute responses may be inferred by the increased arterial baroreflex sensitivity. The increase in arterial baroreflex sensitivity may be partly improved by less vascular stiffness [23] caused by aerobic exercise [30]. Other possible mechanisms by the presence of vagal response during $\mathrm{VJ}$ execution in continuous $60 \mathrm{SVJ}$ protocol include: increased endothelial synthesis of nitric oxide, release of prostaglandin and a decline in sympathetic vasoconstrictor tone [32]. It is suggested that these responses may be reasons why the VJ execution, in continuous 60SVJ protocol, reduces arterial stiffness, increases arterial baroreflex sensitivity and reactivates the appearance of vagal tone.

Although it has been shown that there is a relationship between HRV and cardiorespiratory function in athletes and non-athletes [16], this was the first study to demonstrate a moderate correlation $(r=0.7206 ; p=0.04 ; r=0.7942 ; p=$ 0.01 ) between the fatigue index increase in $60 \mathrm{SVJ}$ and the mean height of $5 \mathrm{VJ}$, with a high sympathetic to parasympathetic modulation LF:HF R2 after 5 min effort in team sport athletes, respectively (Figure 3). These tests, besides showing a significant contribution from anaerobic metabolism, also have a considerable contribution of aerobic metabolism. These results are consistent with previous studies that reported low vagal-related HRV indexes after submaximal [31] and supramaximal [6,7] exercises. The absence of the vagal modulation (i.e., increase of the LF:HF ratio) after exertion (30-45 $\mathrm{min}, 75 \% \mathrm{VO} 2 \mathrm{max}$ ) may last for 5 to $10 \mathrm{~min}$ [31], for $10 \mathrm{~min}$ after Wingate test [15] and for 1 hour after 6 intermittent races (3 $\mathrm{min}, 100 \% \mathrm{VO} 2 \max$ ) [6]. Thus, it is reasonable that the results found in this study may be related to a high training load, since the athletes were in the competition period of intense games. It should be noted that even though the basketball players, of the present study, were in the competition period, they showed $\mathrm{VJ}$ mean values of $49.0 \pm 5.8 \mathrm{~cm}$, which is approximately in the range of 
40-75 $\mathrm{cm}$ according to the review study from Ziv and Lidor [39] with basketball players. Still, more research needs to be conducted to verify the responses of HRV during and after real situations of basketball games.

\section{Conclusions}

It is concluded that the $5 \mathrm{VJ}$ test characterized by intermittent high intensity loads, showed high significant responses of sympathetic modulation (LF; LF:HF) compared to the $60 \mathrm{SVJ}$ protocol. The 5 min recovery was not sufficient for the onset of vagal tone, which was accompanied by higher fatigue index presented by basketball athletes.

\section{ACKNOWLEDGEMENTS}

The authors would like to thank to the Macaé Basketball Association Team, IMMT/Macaé and Prof. Henrique Gama by contributions to this study.

\section{Disclosure of Interest}

The authors declare that they have no conflicts of interest concerning this article.

\section{REFERENCES}

[1] American College of Sport's Medicine ACSM's., 2010, Guidelines for Exercise Testing and Prescription, 8th ed. Philadelphia, PA: Wolters Kluwer.

[2] Ben Abdelkrim, N., El Fazaa, S., El Ati, J., 2007, Time-motion analysis and physiological data of elite under-19-year-old basketball players during competition. Br J Sports Med, 41(2), 69-75.

[3] Borresen, J., Lambert, M. I., 2008, Autonomic control of heart rate during and after exercise: measurements and implications for monitoring training status. Sports Med, 38(8), 633-646.

[4] Bosco, C., 1980, Sei un grande atleta: vediano che cosa dice I'Ergojump. Pallavolo, 5, 34-36.

[5] Bosco, C., Luhtanen, P., Komi, P. V., 1983, A simple method for measurement of mechanical power in jumping. European Journal of Applied Physiology and Occupation Physiology, 50(2), 273-282

[6] Buchheit, M., Laursen, P. B., Ahmaidi, S., 2007, Parasympathetic reactivation after repeated sprint exercise. Am J Physiol Heart Circ Physiol, 293(1), H133-141.

[7] Buchheit, M., Millet, G. P., Parisy, A., Pouchez, S., Laursen, P. B., 2008, Ahmaidi S. Supramaximal training and postexercise parasympathetic reactivation in adolescents. Med Sci Sports Exerc, 40(2), 362-371.
[8] Cole, C. R., Blackstone, E. H., Pashkow, F. J., Snader, C. E., Lauer, M. S., 1999, Heart-rate recovery immediately after exercise as a predictor of mortality. N Engl J Med, 341(18), 1351-1357.

[9] Duru, F., Candinas, R., Dziekan, G., Goebbels, U., Myers, J., Dubach, P., 2000, Effect of exercise training on heart rate variability in patients with new-onset left ventricular dysfunction after myocardial infarction. Am Heart J., 140(1), 157-161.

[10] Esco, M. R., Williford, H. N., 2011, Cardiovascular autonomic modulation in collegiate male basketball players. JEPonline, 4(1), 35-42.

[11] Gamelin, F. X., Berthoin, S., Bosquet, L., 2006, Validity of the polar S810 heart rate monitor to measure R-R intervals at rest. Med Sci Sports Exerc. France, 38(5), 887-893.

[12] Goldberger, J. J., Le, F. k., Lahiri, M., Kannankeril, P. J., Nq, J., Kadish, A. H., 2006, Assessment of parasympathetic reactivation after exercise. Am J Physiol Heart Circ Physiol, 290(6), H2446-2452.

[13] Goldsmith, R. L., Bigger, J. T., Steinman, R. C., Fleiss, J. L., 1992, Comparison of 24-hour parasympathetic activity in endurance-trained and untrained young men. J Am Coll Cardiol, 20(3), 552-558.

[14] Goldsmith, R. L., Bloomfeld, D. M., Rosenwinkel, E. T., 2000, Exercise and autonomic function. Coron Art Dis, 11(2), 129-135.

[15] Goulopoulou, S., Heffernan, K. S., Fernhall, B., Yates, G., Baxter-Jones, A. D., Unnithan, V. B., 2006, Heart rate variability during recovery from a Wingate test in adolescent males. Med Sci Sports Exerc, 38(5), 875-881.

[16] Hautala, A. J., Makikallio, T. H., Kiviniemi, A., Laukkanen, R. T., Nissila, S., Huikuri, H. V., 2003, et al. Cardiovascular autonomic function correlates with the response to aerobic training in healthy sedentary subjects. Am J Physiol Heart Circ Physiol, 285(4), H1747-1752.

[17] Hynynen, E., Uusitalo, A., Konttinen, N., Rusko, H., 2008, Cardiac autonomic responses to standing up and cognitive task in overtrained athletes. Int J Sports Med, 29(7), 552-558.

[18] Iellamo, F., Legramante, J. M., Pigozzi, F., Spataro, A., Norbiato, G., Lucini, D., 2002, et al. Conversion from vagal to sympathetic predominance with strenuous training in high-performance world class athletes. Circulation, 105(23), 2719-2724.

[19] Imai, K., Sato, H., Hori, M., Kusuoka, H., Ozaki, H., Yokoyama, H., Takeda, H., Inoue, M., Kamada, T., 1994, Vagally mediated heart rate recovery after exercise is accelerated in athletes but blunted in patients with chronic heart failure. J Am Coll Cardiol, 24(6), 1529-1535.

[20] Kawada, T., Ikeda, Y., Sugimachi, M., Shishido, T., Kawaguchi, O., Yamazaki, T., et al, 1996, Bidirectional augmentation of heart rate regulation by autonomic nervous system in rabbits. Am J Physiol Heart Circ Physiol, 271 (1 Pt 2), $\mathrm{H} 288-\mathrm{H} 295$.

[21] Kiviniemi, A. M., Hautala, A. J., Kinnunen, H., Tulppo, M. P., 2007, Endurance training guided individually by daily heart rate variability measurements. Eur J Appl Physiol, 101(6), 743-751. 
[22] Komi, P. V., Bosco, C., 1978, Utilization of stored elastic energy in leg extensor muscles by men and women. Med Sci Sports, 10(4), 261-265.

[23] Lipman, R. D., Grossman, P., Bridges, S. E., Hamner, J. W., Taylor, J. A., 2002, Mental stress response, arterial stiffness, and baroreflex sensitivity in healthy aging. J Gerontol Ser A Biol Sci Med Sci, 57(7), B279-B284.

[24] Maclaren, D., 1997, Court games: volleyball and basketball. In: Reilly, T., Secher, N., Sell, P., Willians, C., Editors. Physiology of sports. London: E\&FN Spon.

[25] Manzi, V., Castagna, C., Padua, E., Lombardo, M., D’Ottavio, S., Massaro, M., 2009, et al. Dose-response relationship of autonomic nervous system responses to individualized training impulse in marathon runners. Am J Physiol Heart Circ Physiol, 296(6), H1733-1740.

[26] McInnes, S. E., Carlson, J. S., Jones, C. J., McKenna, M. J., 1995, The physiological load imposed on basketball players during competition. J Sports Sci, 13(5), 387-397.

[27] Miyamoto, T., Kawada, T., Takaki, H., Inagaki, M., Yanagiya, Y., Jin, Y., Sugimachi, M., Sunagawa, K., 2003, High plasma norepinephrine attenuates the dynamic heart rate response to vagal stimulation. Am J Physiol Heart Circ Physiol, 284(6), H2412-2418.

[28] Miyamoto, T., Kawada, T., Yanagiya, Y., Inagaki, M., Takaki, H., Sugimachi, M., Sunagawa, K., 2004, Cardiac sympathetic nerve stimulation does not attenuate dynamic vagal control of heart rate via-adrenergic mechanism. Am J Physiol Heart Circ Physiol, 287(2), H860-865.

[29] Mohr, M., Krustrup, P., Bangsbo, J., 2003, Match performance of high-standard soccer players with special reference to development of fatigue. J Sports Sci, 21(7), $519-528$.

[30] Monahan, K. D., Dinenno, F. A., Tanaka, H., Clevenger, C. M., DeSouza, C. A., Seals, D. R., 2000, Regular aerobic exercise modulates age associated declines in cardio vagal baroreflex sensitivity in healthy men. J Physiol, 529(Pt 1), 263-271.
[31] Mourot, L., Bouhaddi, M., Tordi, N., Rouillon, J. D., Regnard, J., 2004, Short- and long-term effects of a single bout of exercise on heart rate variability: comparison between constant and interval training exercises. Eur J Appl Physiol, 92(4-5), 508-517.

[32] Niebauer, J., Cooke, J. P., 1996, Cardiovascular effects of exercise: role of endothelial shear stress. J Am Coll Cardiol, 28(7), 1652-1660.

[33] Oliveira, N. L., Ribeiro, F., Alves, A. J., Teixeira, M., Miranda, F., Oliveira, J., 2013, Heart rate variability in myocardial infarction patients: effects of exercise training. Rev Port Cardiol, 32(9), 687-700.

[34] Ponikowski, P., Anker, S. D., Chua, T. P., Szelemej, R., Piepoli, M., Adamopoulos, S., et al, 1997, Depressed heart rate variability as an independent predictor of death in chronic congestive heart failure secondary to ischemic or idiopathic dilated cardiomyopathy. Am J Cardiol, 79(12), 1645-1650.

[35] Rodacki, A. L. F., Fowler, N. E., Bennett, S. J., 2002, Vertical jump coordination: fatigue effects. Med. Sci. Sports Exerc, 34(1), 105-116.

[36] Rosenwinkel, E. T., Bloomfield, D. M., Arwady, M. A., Goldsmith, R. L., 2001, Exercise and autonomic function in health and cardiovascular disease. Cardiol Clin, 19(3), 369-387.

[37] Sztajizel, J., Jung, M., Sievert, K., Bayes De Luna, A., 2008, Cardiac autonomic profile in different sports disciplines during all-day activity. J Sports Med Phys Fitness, 48(4), 495-501.

[38] Valdivielso, F. N., 1998, La resistenza. Madrid: Gymnos Editorial Deportiva.

[39] Ziv, G., Lidor, R., 2010, Vertical jump in female and male basketball players a review of observational and experimental studies. J Sci Med Sport, 13(3), 332-339. 